\title{
An investigation into factors impacting financial exclusion at the bottom of the pyramid in South Africa
}

\author{
John P Wentzel ${ }^{\mathrm{a}}$, Krishna Sundar Diatha ${ }^{\mathrm{b}}$ and Venkata Seshachal Sarma Yadavalli ${ }^{\mathrm{c}}$ \\ aAdjunct Faculty, Gordon Institute of Business Science, University of Pretoria, South Africa; \\ bProfessor, Production \& Operations Management Area, Indian Institute of Management Bangalore, \\ India; \\ 'Professor, Department of Industrial \& Systems Engineering, University of Pretoria, South Africa.
}

CONTACT Krishna Sundar Diatha Management Bangalore, India 560076

diatha@iimb.ernet.in

\begin{abstract}
Financial exclusion has been shown to have negative socio-economic effects on citizens, especially at the bottom of the economic pyramid. South Africa suffers from high levels of financial exclusion, disproportionately at the bottom of the pyramid. This study investigates nine factors identified from the literature as being positively associated with financial exclusion using a logistic regression model. The findings show that the most significant factors associated with being financially excluded at the bottom of the pyramid in South Africa were educational level, primary source of income, age, home language and number of dependents. The study further found that gender, relationship status and home ownership were not associated with being financially excluded. An interesting finding was that living in a rural area as opposed to an urban area was not significantly associated with being excluded. The findings and their implications for expanding financial inclusion at the bottom of the pyramid are discussed.
\end{abstract}

\section{KEYWORDS}

Financial exclusion; bottom of the pyramid; logistic regression

\section{Introduction}

The term financial exclusion was first used by geographers who were concerned about limited physical access to banking services as a result of bank branch closures in the United Kingdom (Leyshon \& Thrift, 1995). The closure of banking branches resulted in people and certain groups not being able to access the financial services infrastructure. In the absence of alternative providers, these individuals and groups risked becoming excluded from the formal financial services system. Numerous definitions of financial exclusion now exist in the literature. Financial exclusion has been defined as the inability of some societal groups to access the formal financial system (Carbo et al., 2005). According to Conroy (2005) financial exclusion is a process that prevents poor and disadvantaged social groups from gaining access to the formal financial systems of their countries. Mohan (2006) holds that financial exclusion signifies the lack of access by certain segments of the society to appropriate, low-cost, fair and safe financial products and services from main-stream providers. Being financially excluded means households, 
and micro and small enterprises, deal entirely in cash and are susceptible to irregular cash flows. Financial exclusion increases the risk of loss through theft and leaves people at the mercy of predatory practices from unregulated credit providers (Mohan, 2006).

The most basic form of formal financial inclusion is access to a bank account (Finscope, 2010, 2011). People who do not have a basic bank account are thus defined as financially excluded. People who do not have a bank account may, however, make use of informal financial services. A distinction thus needs to be drawn between being totally financially excluded and formal financial exclusion. At a macroeconomic level, financial exclusion can retard economic growth and increase poverty and inequality. It has been shown (Banerjee \& Newman, 1993) that lack of broad access can generate persistent income inequality or poverty traps at a country level. Some researchers (Hulme \& Mosley, 1996; Yunus \& Jolis, 2003) suggest that provisioning of financial services is among the most potent tools to reduce poverty and empower the poor. It has been shown (Sarma \& Pais, 2011) that levels of human development and financial inclusion move in close cor-relation with each other at a country level.

The term 'bottom of the pyramid' was first described in 2002 (Prahalad \& Hart, 2002). The authors divided the global population into four tiers creating a pyramid. At the bottom of the pyramid were four billion people whose per-capita income based on purchasing power parity was less than $\$ 1500$ per annum, the minimum considered necessary to sustain a decent life. Whilst this presented an untapped market for business, investing in the bottom of the pyramid would also mean lifting billions of people out of poverty and desperation. In a subsequent paper, Prahalad \& Hammond (2002) argued that people at the bottom of the pyramid pay higher prices for goods and services compared with middle-class consumers. Prahalad (2006) argued that serving bottom-of-the pyramid cus-tomers was not only a profitable opportunity for business, but also a social imperative. By addressing the problems at bottom of the pyramid, poverty and the living conditions of the world's poorest could be improved (Prahalad, 2006).

\section{Research problem}

Studies into financial exclusion in South Africa (Finscope, 2010, 2011) found that at least $27 \%$ of the population was financially excluded, as they did not hold a bank account. This portion of the population is referred to as the unbanked. The ability to identify demographic factors associated with being unbanked would allow easier identification of vulnerable populations and enable more targeted intervention to address the problem of being unbanked at the bottom of the pyramid. Research into factors associated with finan-cial exclusion has been reported previously.

Gender, social class, age, marital status, household income, ethnicity, region, educational attainment, employment status, housing tenure and number of people in the household were all factors associated with financial exclusion in the United Kingdom (Devlin, 2005). Research in the United States found that gender, net worth, age and house-hold size had an impact upon bank financial services ownership (Hogarth \& O’Donnell, 1997). Research in Europe has shown that financial exclusion among households has very strong links to low income and age, with the youngest and oldest people in society being the most likely to be excluded (European Commission, 2010). Geography has also been reported as being associated with financial exclusion with 
regional variations reported in the United States (Hogarth \& O'Donnell, 1997) and some evidence of regional variations in the United Kingdom (Kempson et al., 2000). Housing tenure was shown to be the second most important influence on total financial exclusion, with those in social housing - either housing association or, in particular, local authority housing - far more likely to be excluded (Devlin, 2009).

Similar studies into financial exclusion have been conducted in emerging economies such as South Africa. In studying financial exclusion in Latin America (Solo, 2008)it was found that there was a correlation between being unbanked and lower education and income levels compared with banked people. In rural India, women have remained considerably more deprived of basic banking services as compared with men (Chavan, 2008), suggesting a gender association for financial exclusion. In Kenya and Uganda people in the 18 to 24 age category were significantly more likely to be financially excluded when compared with other age groups (Johnson \& Nino-Zarazua, 2011). Further studies in Kenya found income, education level, gender and location associated with being financially excluded (Johnson \& Arnold, 2010). A study into financial exclusion in Nigeria (Amaeshi, 2006) found that education levels - in particular, illiteracy - were strongly associated with financial exclusion. In Ghana, a study into financial exclusion in rural communities found that it was associated with, among other factors, illiteracy, dependency and unemployment (Osei-Assibey, 2009).

From the literature survey, numerous factors have been identified as being associated with financial exclusion. Using the literature review as a basis, the authors identified eight demographic factors highlighted in previous studies as possibly associated with being financially excluded. These factors were gender, age, primary source of income, home ownership status, marital status, highest level of education attained, the number of dependents supported by the respondent and geographic location. With 11 official languages in South Africa, the authors also decided to investigate whether there was an association between home language and financial exclusion.

\section{Methodology}

The research sought to study bottom-of-the-pyramid people, so there was a need to segment the population in a meaningful way to identify bottom-of-the-pyramid respondents. It was decided to use the Living Standards Measure (LSM) to segment the South African population and identify the sample that met the criteria for bottom of the pyramid. The South African Advertising Research Foundation developed the LSM methodology in the 1980s for market segmentation. The LSM methodology classifies the popu-lation into 10 categories from LSM 1 to LSM 10. It is a household-level multiattribute tool that uses access to services, durables and geographic indicators as determinants of the standard of living of a household. The LSM tool has been widely used for market segmen-tation and understating living conditions in South Africa (Møller, 1997; De Jager, 2004; Martins, 2004). One of the advantages of the methodology is the avoidance of self-reported income as a basis for segmenting the population. The All Media and Products Survey 2011 data on average household income as a function of LSM was used to determine the LSM cut-off value for the bottom of the pyramid (South Africa Advertising Research Foun-dation, 2011). The original definition of per-capita income was based on purchasing power parity, and the average dollar/rand exchange rate 
for 2011 was used to calculate the dollar equivalent of the per-capita income. From the analysis it was found that LSM 1 to LSM 4 cover the bottom of the pyramid in South Africa.

Data were drawn as a subset from those collected as part of continuing research on the bottom of the pyramid in South Africa. Data collection took the form of an administered questionnaire delivered at the respondent's place of residence. The approach of using administered questionnaires offered advantages over alternative approaches. The approach is potentially the least burdensome on the respondent and merely requires the respondent to speak the same language in which the questions are asked. Administered questionnaires also score higher for completeness than alternative approaches (Bowling, 2005). The pre-testing of the questionnaire was done systematically using face validity and content validity, as recommended by Cavana et al. (2001). The focus of the questionnaire was to understand the respondent in the context of their household and community, their access to financial services infrastructure and their demographics. The final questionnaire consisted of 14 sections, contained 95 questions and took on average 45 minutes to administer.

The sampling methodology sought to obtain a country representative sample from the bottom of the pyramid. To ensure that the sample geographically represented the overall population, the classification of the entire country by enumerator areas (EAs) was used as the basis for calculating the sample plan (Statistics South Africa, 2003). A total of 650 EAs were analysed for total population and an average LSM was determined. Using these data, the appropriate EAs were selected and the number of required responses per EA was determined. Using the resultant data, the sample was drawn proportional to population size in that EA. Between four and six interviewers were assigned per EA. To correctly identify respondents, two further levels of random sampling were deployed. Within each EA, households were randomly selected and individual respondents were then ran-domly selected from adults in each sampled household using the Kish grid method (Kish, 1949). This approach has also been followed by other studies into financial inclusion in South Africa (Finscope, 2010, 2011).

The data collection produced a total of 1997 completed questionnaires covering LSM 1 to LSM 6. From the LSM classification it was determined that 615 respondents in the sample could be classified as bottom of the pyramid. Based on the All Media and Products Survey 2011 data, the total LSM 1 to LSM 4 population of adults 15 years and older in South Africa was 10542000 . The data consequently had a $3.72 \%$ confidence interval at a $95 \%$ confidence level. Out of the sample of 615 , a total of $276(44.9 \%)$ did not hold bank accounts. The nine independent variables (age, gender, residential area, home ownership status, home language, number of dependents, primary source of income, highest level of education attained and relationship status) were a mixture of dichotomous, categorical and continuous variables.

Age was determined from date of birth and was a continuous variable. Gender was a dichotomous variable (male or female), as was residential area (urban or non-urban). The remaining variables were categorical. The authors used the descriptors and definitions used in previous studies into financial exclusion (Finscope, 2010, 2011) to determine the categories for the remaining variables. The result was 15 categories for primary source of income, six categories for relationship status, seven categories for highest educational attainment, five categories for home ownership status, seven categories for number of dependents and 12 categories for home language. 


\section{Results}

A total of 615 respondents comprised the dataset, of which $55.1 \%$ held a bank account and $44.9 \%$ did not. Table 1 presents the frequency measures for the key variables in the study.

Table 1. Frequency measures for the key variables.

\begin{tabular}{|c|c|c|c|c|}
\hline Variable & Value & Frequency & $\%$ & Cumulative $\%$ \\
\hline \multirow[t]{3}{*}{ Gender } & Female & 382 & 61.2 & 61.2 \\
\hline & Male & 233 & 37.9 & 100.0 \\
\hline & Total & 693 & 100.0 & \\
\hline \multirow[t]{3}{*}{ Area } & Metropolitan & 132 & 21.5 & 21.5 \\
\hline & Non-metropolitan & 483 & 78.5 & 100.0 \\
\hline & Total & 615 & 100.0 & \\
\hline \multirow[t]{6}{*}{ Home ownership } & Owns home with a mortgage & 5 & 0.8 & 0.8 \\
\hline & Owns home without a mortgage & 445 & 72.4 & 73.2 \\
\hline & Rents the home & 46 & 7.5 & 80.7 \\
\hline & Does not own and not paying rent & 100 & 16.3 & 96.9 \\
\hline & Other & 19 & 3.1 & 100.0 \\
\hline & Total & 615 & 100.0 & \\
\hline \multirow[t]{7}{*}{ Primary source of income } & Formal employment & 129 & 21.0 & 21.0 \\
\hline & Money from others & 113 & 18.4 & 39.3 \\
\hline & Government grants & 247 & 40.2 & 79.5 \\
\hline & Informal employment & 84 & 13.7 & 93.2 \\
\hline & Self-employment & 33 & 5.4 & 98.5 \\
\hline & Other & 9 & 1.5 & 100.0 \\
\hline & Total & 615 & 100 & \\
\hline \multirow[t]{8}{*}{ Number of dependents } & 0 & 53 & 8.6 & 8.6 \\
\hline & 1 & 151 & 24.6 & 33.2 \\
\hline & 2 & 113 & 18.4 & 51.5 \\
\hline & 3 & 107 & 17.4 & 68.9 \\
\hline & 4 & 75 & 12.2 & 81.1 \\
\hline & 5 & 48 & 7.8 & 88.9 \\
\hline & 6 or more & 68 & 11.1 & 100.0 \\
\hline & Total & 615 & 88.9 & \\
\hline \multirow[t]{12}{*}{ Language } & Afrikaans & 39 & 6.3 & 6.3 \\
\hline & English & 2 & 0.3 & 6.6 \\
\hline & IsiNdebele & 11 & 1.8 & 8.5 \\
\hline & IsiXhosa & 141 & 22.9 & 31.4 \\
\hline & IsiZulu & 155 & 25.2 & 56.6 \\
\hline & Sepedi & 79 & 12.8 & 69.4 \\
\hline & Sesotho & 50 & 8.1 & 77.6 \\
\hline & Setswana & 60 & 9.8 & 87.3 \\
\hline & SiSwati & 23 & 3.7 & 91.1 \\
\hline & Tshivenda & 23 & 3.7 & 94.8 \\
\hline & Xitsonga & 32 & 5.2 & 100 \\
\hline & Total & 615 & 100 & \\
\hline \multirow[t]{7}{*}{ Relationship status } & Married or living together & 200 & 32.5 & 32.5 \\
\hline & Single or never married & 322 & 52.4 & 84.9 \\
\hline & Widowed & 65 & 10.6 & 95.4 \\
\hline & Separated & 17 & 2.8 & 98.2 \\
\hline & Divorced & 10 & 1.6 & 99.8 \\
\hline & Other & 1 & 0.2 & 100.0 \\
\hline & Total & 615 & 100.0 & \\
\hline \multirow[t]{8}{*}{ Education } & No schooling & 42 & 6.8 & 6.8 \\
\hline & Primary schooling & 139 & 22.6 & 29.4 \\
\hline & Some high schooling & 295 & 48.0 & 77.4 \\
\hline & Matric & 120 & 19.5 & 96.9 \\
\hline & Apprenticeship & 4 & 0.7 & 97.6 \\
\hline & Diploma & 10 & 1.6 & 99.2 \\
\hline & University degree & 5 & 0.8 & 100.0 \\
\hline & Total & 615 & 100.0 & \\
\hline
\end{tabular}


In the sample, $62.1 \%$ of the respondents were female and $37.9 \%$ male. This ratio is higher than the reported ratio for the country, which is $51.5 \%$ female and $48.5 \%$ male (Statistics South Africa, 2012). The reason for the difference between the two numbers is not immediately apparent, but may be related to the time of day when agents visited the homes. Interviews were conducted during the day and males may have been away working. Another possible explanation in rural areas is that males may be away working in urban areas and thus no males were living in the home at the time of the interview. The average age of respondents was 39.5 years with a standard deviation of 16.3 years. The results showed that the majority of bottom-of-the-pyramid citizens live in rural areas. Only $21.5 \%$ of respondents were found to be living in urban areas. Education attainment at the bottom of the pyramid showed a significant failure to complete formal schooling. Only $22.6 \%$ of respondents report having completed school-ing, and only $3.1 \%$ reported having completed further education such as an apprentice-ship or tertiary qualification. The problem of formal unemployment at the bottom of the pyramid is also evident. Only $21 \%$ of respondents held a formal job, with a further $13.7 \%$ holding an informal job. In recent years the South African government has significantly expanded its grant programme, and the effect of this can be clearly seen. Some $40.2 \%$ of respondent report that government grants (child support, old age pension and disability grants) were their primary source of income. The dependence for the bottom of the pyramid on friends and family as primary sources of income is also seen, with $18.4 \%$ of respondents dependent on friends and family as their primary source of income.

The study sought to determine which, if any, of the nine variables were statistically associated with being unbanked at the bottom of the pyramid in South Africa. The depen-dent variable, being unbanked (UN), is dichotomous in that a respondent is either banked or unbanked. Respondents who did not know their banking status were excluded from the study. The nine independent variables of interest were either dichotomous (residential area, gender) or categorical (age, marital status, highest level of education, primary source of income, number of dependents, home language, home ownership status). The independent variable age was recorded as a continuous variable, but recoded into cat-egories. This was done in order to compare the results with banking usage results reported previously (Finscope, 2010, 2011) which used the same age categories. In order to test the relationship between the dichotomous dependent and dichotomous and categorical independent variables, a logistic regression was chosen to conduct the investigation. A logistic regression is well suited to describing or testing a hypothesis between categorical or dichotomous independent and dependent variables (Peng et al., 2002). A logistic regression does not make any assumptions of normality, linearity or homogeneity for the independent variables and is well suited for analysing dichotomous outcomes (Peng \& So, 2002, Peng et al., 2002). Logistic regression has further been successfully used to identify variables associated with financial exclusion (Devlin, 2009; Johnson \& Nino-Zarazua, 2011).

For the logistic expression the independent variable was unbanked (UN). The dependent variables were age $(A)$, gender $(G)$, residential area $(R)$, home ownership status $(H)$, primary source of income (I), number of dependents (D), home language (L), relationship status (M) and highest level of educational attainment (E). The form of the equation was 
thus:

$$
\mathrm{UN}=f(A, G, R, H, I, D, L, M, E)
$$

To conduct the analysis IBM, SPSS Statistics 20.0.0 software was used. The standard dummy variable technique was applied in which the first mentioned category is used as the reference category in the final equation. The approach generates coefficients, standard errors and significance levels of a predicted logit transformation of the probability of presence of the variable of interest. The logistic expression used was thus:

$$
\operatorname{logit}(p \mathrm{UN})=b_{0}+b_{1} A+b_{2} G+b_{3} R+b_{4} H+b_{5} I+b_{6} D+b_{7} L+b_{8} M+b_{9} E
$$

where pUN is the probability of being unbanked and bi are the coefficients of the expression. To assess whether the expression was a good fit to the observed data, the Hosmer \& Lemeshow (2000) goodness-of-fit statistic was used. Use of the Hosmer and Lemeshow statistic was appropriate because the independent variables were categorical or dichotomous. While the logistic regression may indicate a good overall fit of the variables to the data, it is by no means certain that each variable in the logistic expression is significant. In order to determine the significance of individual coefficients in the logistic expression, the Wald Test was used (Polit, 1996; Agresti, 2007). The Wald test determines whether the parameters associated with a group of explanatory variables is zero. If, for a particular explanatory variable or group of explanatory variables, the Wald test is signifi-cant then it can be concluded that the parameters associated with these variables are not zero. Consequently, the variables have explanatory power in the logistic expression. If the Wald test is not significant then these explanatory variables can be omitted from the expression.

The results of the logistic regression are presented in Table 2. In this table, B is the coefficient for the variable and S.E. the standard error around the coefficient. The column 'Sig.' is the statistical significance of the variable. The categorical variables home ownership status (H), primary source of income (I), number of dependents (D), home language (L), relationship status $(\mathrm{M})$ and highest level of educational attainment (E) were

\begin{tabular}{|c|c|c|c|c|c|c|}
\hline Variable & B & S.E. & Wald & df & Sig. & $\operatorname{Exp}(B)$ \\
\hline Age $(A)$ & 0.027 & 1.330 & 9.967 & 1 & 0.002 & 0.015 \\
\hline Gender (G) & 0.249 & 0.234 & 1.128 & 1 & 0.288 & 1.283 \\
\hline Area $(\mathrm{R})$ & 0.380 & 0.265 & 2.064 & 1 & 0.151 & 1.463 \\
\hline Home ownership $(\mathrm{H})$ & & & 2.766 & 4 & 0.598 & \\
\hline Source of income (I) & & & 50.405 & 14 & 0.000 & \\
\hline Number of dependents (D) & & & 13.538 & 6 & 0.035 & \\
\hline Language $(\mathrm{L})$ & & & 19.698 & 10 & 0.032 & \\
\hline Marital status (M) & & & 0.411 & 5 & 0.995 & \\
\hline Educational level (E) & & & 48.367 & 6 & 0.000 & \\
\hline \multirow[t]{2}{*}{ Constant } & -4.198 & 1.330 & $\begin{array}{c}9.967 \\
\text { Predicted }\end{array}$ & 1 & 0.002 & 0.015 \\
\hline & & \multicolumn{2}{|c|}{ Banking status } & Percentage correct & & \\
\hline Observed & & No & Yes & & & \\
\hline \multirow[t]{2}{*}{ Banking status } & No & 179 & 97 & 64.9 & & \\
\hline & Yes & 84 & 255 & 75.2 & & \\
\hline Overall percentage & & & & 70.6 & & \\
\hline
\end{tabular}

Table 2. Results of the logistic regression.

Hosmer and Lemershow test: step 1, chi-square $=5.243, \mathrm{df}=8$, sig. $=0.731$. 
modelled using the standard dummy variable procedure in SPSS. As a consequence there is no coefficient listed in the table because they were not variables in the equation. Dummy variables, which code for these variables, have coefficients. The recommended format of previous authors (Peng et al., 2002) was used in reporting the results of the logistic regression.

The test of the logistic regression against a constant was found to be significant. The Hosmer and Lemeshow goodness-of-fit statistic was 0.731 , which was significant. The result indicates that the variables as a set reliability distinguish between being banked and unbanked at the bottom of the pyramid in South Africa. The overall prediction success of the expression was $70.6 \%$. The logistic expression correctly predicted being unbanked $75.2 \%$ of the time and being banked $64.9 \%$ of the time. The Wald criterion for each of the variables in the expression was also determined. The variable is significant in the expression if the significant of the Wald statistic is significant at the $p<0.05$ level. Of the nine variables in the logistic expression, four were found not to be significant at the $\mathrm{p}<$ 0.05 level. These variables were residential area $(R)$, gender $(G)$, home ownership status $(\mathrm{H})$ and relationship status $(\mathrm{M})$. The remaining variables in the expression - home language (L), number of dependents (D), age (A), primary source of income (I) and highest educational attainment $(\mathrm{E})$-were found to be significant.

The logistic analysis was repeated with the four non-significant variables - area (R), gender $(\mathrm{G})$, home ownership status $(\mathrm{H})$ and relationship status $(\mathrm{M})$ - removed. The Hosmer and Lemeshow goodness-of-fit improved slightly to 0.759 . The overall prediction success of the expression declined slightly to $70.2 \%$. The logistic expression correctly pre-dicted being unbanked $74.0 \%$ of the time and being banked $65.6 \%$ of the time. The Wald criterion for each of the remaining variables in the expression was also determined, and they showed little movement in the values or significance of the Wald statistics. The analy-sis confirmed that the four non-significant variables had no meaningful impact on the pre-diction of being unbanked at the bottom of the pyramid in South Africa. Table 3 presents the Wald statistic and significance level of each of the five independent variables in the logistic equation. The use of both values allows a determination of which variables are the most significant in predicting being unbanked at the bottom of the pyramid in South Africa.

Table 3. Results of the logistic regression with significant variables.

\begin{tabular}{|c|c|c|c|c|c|c|}
\hline Variable & B & S.E. & Wald & df & Sig. & $\operatorname{Exp}(B)$ \\
\hline Age $(A)$ & 0.027 & 0.010 & 7.099 & 1 & 0.008 & 1.027 \\
\hline Source of Income (I) & & & 50.713 & 14 & 0.000 & \\
\hline Number of dependents (D) & & & 14.340 & 6 & 0.026 & \\
\hline Language (L) & & & 22.814 & 10 & 0.011 & \\
\hline Educational level (E) & & & 51.238 & 6 & 0.000 & \\
\hline \multirow[t]{3}{*}{ Constant } & 0.886 & 1.866 & 0.226 & 1 & 0.635 & 2.426 \\
\hline & \multicolumn{4}{|c|}{ Predicted } & & \\
\hline & & \multicolumn{2}{|c|}{ Banking Status } & \multirow{2}{*}{$\begin{array}{c}\text { Percentage } \\
\text { Correct }\end{array}$} & & \\
\hline Observed & & No & Yes & & & \\
\hline \multirow[t]{2}{*}{ Banking status } & No & 181 & 95 & 65.6 & & \\
\hline & Yes & 88 & 251 & 74.0 & & \\
\hline Overall percentage & & & & 70.2 & & \\
\hline
\end{tabular}

Hosmer and Lemershow test: Step $=1$, chi-square $=4.989, \mathrm{df}=8$, sig. $=0.759$. 
From the significant values it can be seen that the highest level of education attainment (E) is the most significant independent variable in the expression with $\mathrm{p}<0.000$ and a Wald value of 51.238. This is closely followed by primary source of income (I). The age (A) of the respondents and their home language (L) follow in order of significance, followed by the number of dependents (D) that is the least significant.

The findings shows that the most significant variables associated with being unbanked at the bottom of the pyramid in South Africa were education level, primary source of income, age, home language and number of dependents. Education level was the most significant predictor of being unbanked. We observed a correlation between level of educational attainment and being unbanked. In total, $71.4 \%$ of respondents with no schooling were unbanked compared with $26.6 \%$ of respondents who had completed Matric. Respondents who had some form of tertiary education (apprenticeship, diploma or university degree) had the lowest level of being unbanked (15.8\%).

The second most significant variable associated with being unbanked was primary source of income. Respondents who were formally or self-employed had significantly lower levels of being unbanked than respondents who depended on government grants, informal employment or depended on family, friends or partners for their income. The lowest levels of unbaked were recorded in respondents who were formally employed, with only $22.5 \%$ being unbanked. Respondents who were self-employed (farming, money from their own business, money from renting or from selling goods on the street) were found to be $30.3 \%$ unbanked. The highest levels of unbanked were found in respondents who held informal jobs (59.5\%) and those who depended on family, friends or partners as their primary source of income (59.3\%).

To make a determination of the extent of age correlation with being unbanked, the age variable was converted into a categorical variable. For comparative reasons, the same age bins as reported in similar studies into financial inclusion in South Africa (Finscope, 2010,2011 ) were used. The result showed that respondents younger than 25 years old and older than 65 years had higher rates of being unbanked than other age groups. For respondents younger than 25 years, some $53.7 \%$ were unbanked. For respondents older than 65 years, some $60 \%$ were unbanked. Unbanked portion in the remaining age categories ranged from $43.7 \%$ (ages 25 to 34 ) to the lowest of $37.1 \%$ (ages 35 to 44 ).

Regarding the number of dependents it was found that the percentage of unbanked respondents was highest for those who had no dependents. For respondents who had one or more dependents, the unbanked percentages were all lower than $50 \%$. The lowest levels of unbanked among respondents were those with four dependents, where 33.3\% unbanked. The highest level of being unbanked among respondents was for those who had two dependents, where $49.6 \%$ were unbanked. The analysis of home language and being unbanked was compromised by small sample sets for some of the languages. The languages English and isiNdebele had very small sample sizes and conse-

quently it was not feasible to attempt a determination of which home language was more strongly associated with being unbanked at the bottom of the pyramid.

\section{Conclusion}

The results of the research highlight that understanding financial exclusion at the bottom of the pyramid is complex. Some aspects of the findings support previous studies in 
different geographies, but other aspects do not. This may imply that the circumstances and reasons behind financial exclusion at the bottom of the pyramid in one area may be different from another area. It further implies that solutions to address financial exclusion that work in one region may not work in another. Given the differences in socio-economic conditions across countries it may thus be expected that financial exclusion will be driven by different factors in different countries.

The study's finding that educational attainment is most correlated with financial exclusion also provides a potential way forward in addressing the problem. One of the ways of reducing financial exclusion at the bottom of the pyramid in South Africa may be to focus on education rather than physical access exclusively. The more educated a respondents was, the less likely they were to be financially excluded. The work may further suggest that it could be beneficial to teach financial literacy and the role of banking early in the school curriculum. This could assist students who do not complete their formal education to have a basic understanding of the financial system and the benefits that having a bank account may bring. The finding that primary source of income is correlated with financial exclusion also provides interesting insights. Increasing levels of formal employment may reduce levels of financial exclusion. It provides a further impetus for addressing the current chronic unemployment in South Africa.

Our findings show that age is correlated with financial exclusion in South Africa. It thus partially supports the findings based on US data (Hogarth \& O'Donnell, 1997). Respondents aged 16 to 25 were more likely to be excluded compared with other age groups. Part of the reason for this may be the very low levels of formal employment in this age group. Only $9.3 \%$ of respondents in this age group were formally employed while $69.3 \%$ of respondents were dependent on receiving money from others. The extremely high levels of unemployment and dependence on others may render the need for a bank account moot, but the results also points to a significant problem of youth unemployment at the bottom of the pyramid. The finding of an association between home language and financial exclusion was surprising. Whilst the sample size was too small to determine which official languages were more associated with financial exclusion, it provides an interesting area for further study. The findings also highlight that providers need to be aware of the language in which they engage prospective clients.

A relationship between gender and being financially excluded was not found. This finding does not support previous work (Hogarth \& O’Donnell, 1997), which found a heterogeneous relationship between gender and financial exclusion in the United States, nor work which reported gender differences in Kenya and Uganda (Johnson \& NinoZarazua, 2011) or India (Chavan, 2008). Marital status and home ownership status were found to be unimportant in explaining exclusion. A more interesting finding is that location (i.e. living in a rural as opposed to an urban area) is not associ-ated with being financially excluded. This contradicts the sense that building more access channels to financial services in non-urban areas will reduce financial exclusion. The study instead point to a different conclusion. It may be that factors associated with being financially excluded, such as low levels of education and high levels of unemployment, are more prevalent in rural areas than urban areas. Addressing these factors may have a greater impact on reducing financial exclusion in rural areas than attempting to provide greater access to financial services. 


\section{Disclosure statement}

No potential conflict of interest was reported by the author.

\section{References}

Agresti, A, 2007. An introduction to categorical data analysis. Wiley, Hoboken, NJ.

Amaeshi, K, 2006. Financial exclusion, financial institutions and corporate social responsibility: A developing country perspective. doi:10.2139/ssrn.950989.

Banerjee, A \& Newman, A, 1993. Occupational choice and the process of development. Journal of Political Economy 101(2), 274-298.

Bowling, A, 2005. Mode of questionnaire administration can have serious effects on data quality. Journal of Public Health 27(3), 281-291.

Carbo, S, Gardener, P \& Molyneux, P, 2005. Financial exclusion. Palgrave Macmillan Studies in Banking and Financial Institutions. Palgrave Macmillan, New York.

Cavana, R, Delahye, BL, \& Sekaran, U, 2001. Applied business research: Qualitative and quantitative methods. Wiley, Milton, Australia.

Chavan, P, 2008. Gender inequality in banking services. Economic and Political Weekly, 43(47), $22-28$.

Conroy, J, 2005. APEC and financial exclusion: Missed opportunities for collective action? AsiaPacific Development Journal 12(1), 53-79.

De Jager, N, 2004. The living standards measure as a market segmentation tool for selected retailers. North-West University, Potchefstroom Campus, Potchefstroom.

Devlin, J, 2005. A detailed study of financial exclusion in the UK. Journal of Consumer Policy 28, 75-108.

Devlin, J, 2009. An analysis of influences on total financial exclusion. The Service Industries Journal 29(8), 1021-1036.

European Commission, 2010. Financial Exclusion in the EU: New Evidence from the EU-SILC Special Module. Research Note 3/2010

Finscope, 2010. Finscope South Africa 2010. Finmark Trust, Johannesburg, South Africa.

Finscope, 2011. Finscope South Africa 2011. Finmark Trust, Johannesburg, South Africa.

Hogarth, J, \& O'Donnell, K, 1997. Being accountable: A descriptive study of unbanked households in the U.S. Proceedings of the Association for Financial Counseling and Planning Education (AFCPE), 17-20 December, San Diego, California, USA, 58-67.

Hosmer, D, \& Lemeshow, S, 2000. Applied logistic regression. Wiley, New York.

Hulme, D, \& Mosley, P, 1996. Finance against poverty, Volume 1. Routledge, London. Johnson,

S, \& Arnold, S, 2010. Financial exclusion in Kenya: Examining the changing picture, 2006-2009. In Financial inclusion in Kenya: Survey results and analysis from FinAccess 2009.

Johnson, S, \& Nino-Zarazua, M, 2011. Financial access and exclusion in Kenya and Uganda. Journal of Development Studies 47(3), 475-496.

Kempson, E, Whyley, C, Caskey, J, \& Collard, S, 2000. In or out? Financial exclusion: A literature and research review. In Consumer Research. Consumer Policy and Research Department, Financial Services Authority, London. Vol. 3, 5-100.

Kish, L, 1949. A procedure for objective respondent selection within the household. Journal of the American Statistical Association 44(247), 380-387.

Leyshon, A \& Thrift, N, 1995. Geographies of financial exclusion: Financial abandonment in Britain and the United States. Transactions of the Institute of British Geographers 20(3), 312-341.

Martins J, 2004. Household income and expenditure in Gauteng by Living Standards Measure (LSM) Group, 2003. Issue 332 of Research report. Bureau of Market Research, University of South Africa, Pretoria.

Mohan, R, 2006. Economic growth, financial deepening and financial inclusion. Reserve Bank of India, Bulletin Nov, 1305-1319.

Møller, V, 1997. Quality of life in South Africa. Vol 1 of Social Indicator Research Series. Kluwer Academic Publishers, Dordrecht, the Netherlands. 
Osei-Assibey, E, 2009. Financial exclusion: What drives supply and demand for basic financial services in Ghana? Savings and Development 3, 207-238.

Peng, C, \& So, T, 2002. Logistic regression analysis and reporting: A primer. Understanding Statistics: Statistical Issues in Psychology, Education, and the Social Sciences 1(1), 31-70.

Peng, C-Y, Lee, K, \& Ingersoll, G, 2002. An Introduction to Logistic Regression Analysis and Reporting. The Journal of Educational Research 96(1), 3-14.

Polit, D, 1996. Data analysis and statistics for nursing research. Appleton and Lange, Stamford, CT.

Prahalad, C, 2006. The fortune at the bottom of the pyramid. Pearson Prentice Hall, Upper Saddle River, NJ.

Prahalad, C \& Hammond, A, 2002. Serving the world's poor profitability. Harvard Business Review Sept, 48-57.

Prahalad, C \& Hart, S, 2002. The fortune at the bottom of the pyramid. Strategy+Business 26(1), 1-26.

Sarma, M, \& Pais, J, 2011. Financial inclusion and development. Journal of International Development 23, 613-628.

Solo, T, 2008. Financial exclusion in Latin America-or the social costs of not banking the urban poor. Environment and Urbanization 20(1), 47-66.

South Africa Advertising Research Foundation, 2011. LSM Description Slides - March 2011. http:// www.saarf.co.za/LIFESTYLE/lifestyle.htm Accessed 12 January 2012.

Statistics South Africa, 2003. Census 2001: Concepts and definitions. Statistics South Africa, Pretoria.

Statistics South Africa, 2012. Census 20011 Statistical release - P0301.4. Statistics South Africa, Pretoria.

Yunus, M, \& Jolis, A, 2003. Banker to the poor: Micro-lending and the battle against world poverty. New York: PublicAffairs. 